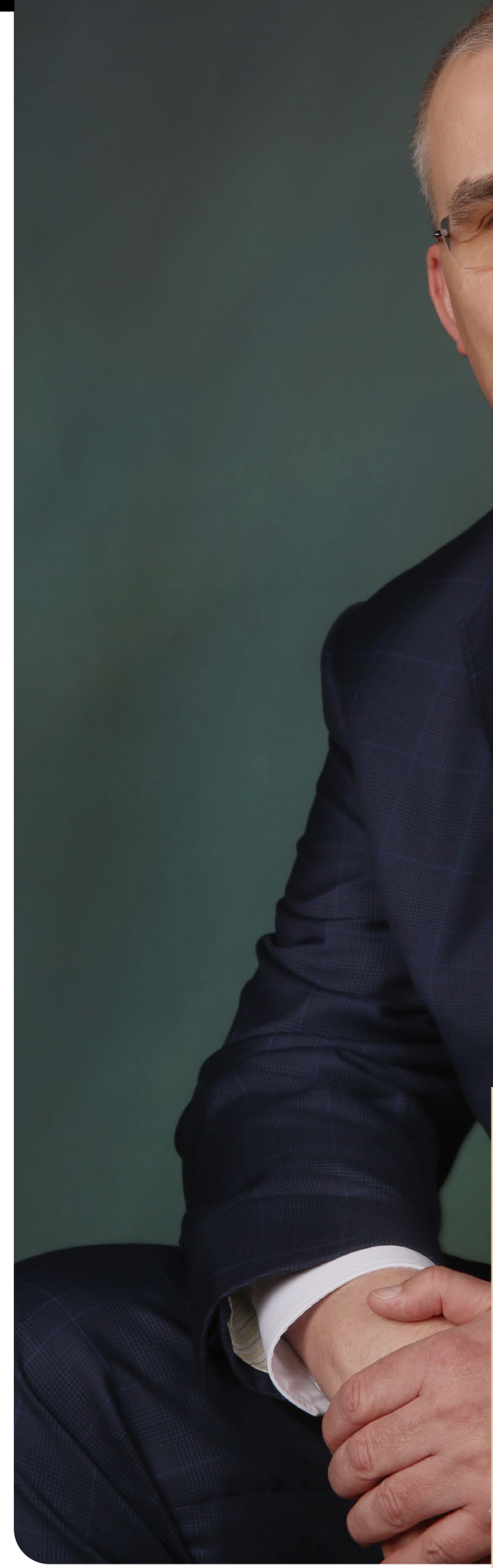

„Mobilität ist im Wandel,

Effizienz bezüglich der eingesetzten Ressourcen, Energie und Platzbedarf ist stärker gefragt als je zuvor. Hier bringen wir uns ein, mit Innovationen und Methodik aus der Automobilindustrie." 


\section{Die Mobilität der Zukunft muss effizient sein}

\section{Prof. Dr. Uwe Dieter Grebe, AVL List}

$\mathrm{D}$ as Benutzen eines Automobils war noch nie so bequem wie heute. Gleichzeitig war es aber wohl noch nie zuvor so komplex. Neben den immer ausgefeilteren Vorgaben für Sicherheit und Umweltverträglichkeit der Fahrzeuge hat sich der Fahrer mit einer Vielzahl von Fragen zu beschäftigen, die sich aus der Nutzung des öffentlichen Raumes ergeben.

So war die vergangene Dekade in der Automobilindustrie geprägt durch das Infragestellen des Geschäftsmodells und der Tätigkeitsschwerpunkt wurde zumindest ein Stück weit verschoben; von Hardware zu Software, von Produkt zu Dienstleistung.

Der Wandel des Fahrzeugherstellers zum Mobilitätsanbieter hat sich allerdings nicht in dem Maße vollzogen, wie dies teilweise prognostiziert wurde. Auch auf Nutzerseite wurde der Wandel des Mobilitätssystems nicht in der erwarteten Art angenommen. Im Gegenteil, die Zahl der Fahrzeuge im Individualverkehr ist in den letzten 20 Jahren in Europa um 25 \% gewachsen, die der Linienbusse dagegen nicht einmal um $5 \%$.

Zuletzt hat die Verbreitung des Covid-19-Virus zu einer sehr deutlichen Verschiebung der Nutzerpräferenzen zugunsten des Individualverkehrs (Auto und Fahrrad) geführt, während öffentliche und private Sammelverkehre erhebliche Einbrüche zu verzeichnen hatten.

Die Herausforderung für Mobilitätsdienstleister, ob öffentlich oder privat, ist ein Angebot, das in wesentlichen Belangen die Bedürfnisse der Nutzer erfüllt. Es ist enorm wichtig, dies in den Mittelpunkt der Anstrengungen zu stellen und sich ehrlich um eine Verbesserung des Angebots zu bemühen, statt die Vorteilhaftigkeit der poli- tisch gewollten Mobilitätslösung mit Verboten und Einschränkungen aller anderen Lösungen zu erzwingen.

Außer dem Bereitstellen von Fahrzeugen sind technische Innovationen aus der Automobilindustrie bisher nur in geringem Umfang genutzt worden. Diese Werkzeuge und Methoden können aber einen guten Beitrag leisten, wenn sie weiterentwickelt werden, um in Kooperation von Fahrzeugentwicklern, Mobilitätsdienstleistern und Flottenbetreibern den Einsatz der Fahrzeuge zu optimieren und die Spezifikation für zukünftige Fahrzeuge und Infrastruktur zu verbessern. Die Betrachtung von konkreten Mobilitätsketten sollte aus detaillierter technischer Perspektive erfolgen, dazu gehört ein technologie-offener Vergleich möglicher Antriebsarten bezüglich Energieverbrauch und $\mathrm{CO}_{2}$-Emissionen in der gesamten Kette.

Bei derVeränderung, die wir gerade sehen, muss aber eines klar sein: Mobilität wird sich nicht rückwärts entwickeln. Die aktuelle Situation können wir deshalb als Chance begreifen - Ingenieurswissen und Innovationskraft ist begehrtes Kapital.

III

\section{Kurzvita}

Prof. Dr. Uwe Dieter Grebe studierte Maschinenbau an der Technischen Universität in Darmstadt, an der er 1996 auch promovierte.

Von 1991 bis 2012 war er in verschieden Positionen für General Motors / Opel tätig, zuletzt als Executive Director für General Motors Europe.

Seit 2011 arbeitet Uwe Dieter Grebe bei AVL List als Geschäftsführer für die Bereiche Global Business Development, Sales \& International Operations. 